\title{
Application of software for the optimization of the surface shape of nets for chestnut harvesting
}

\author{
Andrea Formato, Giampiero Scaglione, Domenico lanniello \\ Department of Agricultural Science. University of Naples "Fed. II", Portici (NA), Italy
}

\begin{abstract}
In this research conveyance nets for the chestnuts harvest have been considered and the optimization of the surface shape of the chestnuts harvest nets has been performed. Indeed, a steep zone with chestnut trees has been considered, with maximum length of $90 \mathrm{~m}$ and maximum width of $60 \mathrm{~m}$ and the geometric model of the considered zone has been obtained, by mean GIS system and "Archicad 14" program code, obtaining also the soil local slope distribution. The chestnuts fallen have been simulated by mean a "rain device" available in "Sitetopo" program code. This program has allowed to evaluate the rain draining in function of the considered surface slope. Further, the zone with lower quote, for the considered surface, is the zone in that the chestnuts have to be convoyed, "basin zone". Indeed, by mean "Sitetopo" program code, it has been possible to evaluate the rain draining contour-plot, and the conveyance effect, that is, where the rain flow is convoyed. This has been obtained by changing of the net surface slope on that, the rain (simulating the chestnuts) fallen. Indeed the nets have been located following the determined optimal surface. In such way all the fallen chestnuts have been convoyed and picked in a determined zone, "basin zone", and subsequently they have been loaded on the truck for the following workmanships. The evaluated losses have been of around 6-8 \% due to chestnuts entangle or little branches obstacle.
\end{abstract}

\section{Introduction}

The chestnut crops, represents an important resource for the national collectivity, considering also the function that the chestnut crop develops inside the wooded sector (Bassi et al.,2001; Biondi et $a l ., 2001$, Formato et al.,2008;). Since the chestnut production involves different operational phases, they have to be performed in effective

Correspondence: Andrea Formato, Department of Agricultural Science. University of Naples "Fed. II", Via Università 100, 80055 Portici (NA), Italy. E-mail: formato@unina.it

Key words: nets for chestnut harvesting, surface optimizing, net design.

CC Copyright A. Formato et al., 2013

Licensee PAGEPress, Italy

Journal of Agricultural Engineering 2013; XLIV(s2):e82

doi:10.4081/jae.2013.s2.e82

This article is distributed under the terms of the Creative Commons Attribution Noncommercial License (by-nc 3.0) which permits any noncommercial use, distribution, and reproduction in any medium, provided the original author(s) and source are credited. way, keeping in mind all the requirements for the chestnut tree plant. (Bergantz R. 1987 New, 1988, Formato et al.,2011). Numerous farms perform chestnut crop activity using different levels of mechanization (Rutter 1987; Monarca et al.,2004). To make not expensive and efficient this activity, it is necessary to use the best available technologies to rationalize the harvest production (Monarca et al.,2004; Formato et al.,2012). Insofar, it results extremely essential, the analysis and the planning of a system in which the machineries and machines are essential components, for the chestnuts harvest and transport. The promotion of the technological innovations to perform this type of work by mean the use of machineries is aimed to facilitate the work of the operators obtaining a lower risk for them and for the environment. Besides the planning, the organization of the works and the improvement of the roads, inside the chestnut tree plant, allow to develop the activities in the considered plant in way more effective and efficient. The mechanization, therefore, is the most important methods that can be considered to perform in the best way the chestnuts crops. Insofar the purpose of this report is that to put in evidence the systems of chestnuts harvest by nets in the chestnut tree plant, keeping in mind the today's mechanical and technological innovations. In fact, by year in year it becomes more and more pressing the demand to improve the chestnuts harvest in mountainous and forestry zones on which the soil morphological conditions make it absolutely unproductive in terms of cost-proceeds. The most part of the zones for the chestnut cultivation, is characterized by excessive soil slope and by difficulty of access. The chestnut harvest machines available on the market still have notable operational limits as it regards the steep zone of the soil considered, sensibly reducing their performances with soil slope higher than $20 \%$. In such case, only the harvest by mean harvest nets it is possible.

\section{Materials and Methods}

For soil zones with slopes over $25 \%$, it is not possible to use any type of harvesting machine, for which it is possible to perform only the aided harvesting by mean the use of harvest nets and aiding machineries. A method of chestnuts harvest in the steep zones has been studied, testing in the considered chestnut tree plant special types of nets, and using aiding machines: tendering - rewinding machines. Indeed, a steep zone with chestnut trees has been considered, with $90 \mathrm{~m}$ of maximum length and $60 \mathrm{~m}$ of maximum width. Methods for the conveyance and to pick up of the fallen chestnuts have been tested, by mean study aimed to determine the best geometric shape to realize during the layout of nets. Insofar it has been necessary to realize a digital elevation model (DEM) of the zone of the considered soil, starting from the site map with level quotes of the considered zone. (Figure 1 and Figure 2).

A Digital Terrain Model (DTM) is a topographic model of the bare hearth - terrain relief - that can be manipulated by computer programs. The data files contain the spatial elevation data of the terrain in a digital format which usually presented as a rectangular grid. Vegetation, 
buildings and other artificial features are removed digitally, leaving just the underlying terrain, namely the Digital Surface Model (DSM). Satellite provides orthorectified images and aerial photography which can be processed for visualization of terrain conditions in three dimensions (3D), leading to a Digital Elevation Model (DEM). DEMs are used often in Geographic Information Systems (GIS), such as ArcGIS and GRASS GIS system , and are the most common basis for digitally-produced relief maps. While a DSM may be useful for landscape modelling, city modelling and visualization applications, a DTM is often required for flood or drainage modelling, land-use studies, geological applications, and other applications. Common uses of DEM include: extracting terrain parameters, modelling water flow or mass movement (for example, landslides), creation of relief maps, rendering of 3D visualizations, creation of physical models (including raised-relief maps), rectification of aerial photography or satellite imagery, reduction (terrain correction) of gravity measurements (gravimetry, physical geodesy), terrain analyses in geomorphology and physical geography. Several factors are important for quality of DEM-derived products: terrain roughness, sampling density (elevation data collection method), grid resolution or pixel size, interpolation algorithm, vertical resolution, terrain analysis algorithm. The intervals between each of the grid points will always be referenced to some geographical coordinate system. This is usually either latitude-longitude or UTM (Universal Transverse Mercator) coordinate systems. The closer together the grid points are located, the more detailed information will be in the file. The details of the peaks and valleys in the terrain has been better modelled with small grid spacing than when the grid intervals are very large. Elevations other than at the specific grid point locations are not contained in the file. As a result peak points and valley points not coincident with the grid has not been recorded in the file. A DEM can be represented as a raster (a grid of squares, also known as a height-map when representing elevation) or as a vector-based triangular irregular network, generally constructed using the Delauny. The TIN DEM dataset is also referred to as a primary (measured) DEM, whereas the Raster DEM is referred to as a secondary (computed) DEM. TIN's are sets of adjacent, non-overlapping triangles computed from irregularly spaced points (mass point) with $(\mathrm{x}, \mathrm{y}, \mathrm{z})$ coordinates. TIN models are used to provide better control over terrain slope, aspect, surface areas, volumetric and cut-fill analysis and generating contours. Mass points can occur at any location, the more carefully selected, the more accurate model of the surface. Wellplaced mass points occur where there is a major change in the shape of the surface, for example, at the peak of a mountain, the floor of a valley, or at the edge (top and bottom) of cliffs. The TIN model is attractive because of its simplicity and economy and is a significant alternative to the regular raster of the GRID model. The TIN's vector data structure is based on irregularly-spaced point, line and polygon data interpreted as mass points and break-lines and stores the topological relationship between triangles and their adjacent neighbours. Break-lines define and control surface behavior in terms of smoothness and continuity. As their name implies, break-lines are linear features. They have a significant effect in terms of describing surface behavior when incorporated in a surface model such as a TIN. Break-lines can describe and enforce a change in the behavior of the surface. Two types of break-lines are included in this layer: hard and soft. Hard break-lines define interruptions in surface smoothness and are typically used to define streams, ridges, shorelines, building footprints, dams, and other locations of abrupt surface change. Soft break-lines are used to ensure that known "Z" (elevation) values along a linear feature (such as a roadway) are maintained in a TIN. Soft break-lines can also be used to ensure that linear features and polygon edges are maintained in the TIN surface model by enforcing the break-line as TIN edges. Soft break-lines, however, do not define interruptions in surface smoothness. The Delauny triangulation is a proximal method used to generate the TIN. The ver- tices of the contour lines are used as mass points for triangulation. In many cases this will cause the presence of flat triangles in the surface (Figure 3). Subsequently on the considered model the study of the local slopes and of the director cosines has been performed, and it has been possible to determine the accumulation zones, where to install the harvest tank. The manipulation of the considered model (Figure 4) it has been performed by mean "Archicad 14" program code (Figure 5). Further, the chestnuts fallen has been simulated by mean a "rain device" like "Sitetopo" code. In this way, it has been possible to evaluate the draining of the rain simulating the fruits fallen. By mean iterations, it has been possible to obtain the optimal net geometric shape that convoyed the rain (chestnuts fallen) in the desired "basin zone" (Figure 6). Indeed the nets have been located following the determined surface. In such way all the chestnuts have been picked in an only determined zone, "basin zone". Then, the nets have been pretensioned following the surface determined with the design method described above. In such way the chestnuts have been rolled down and converged to a single point inside the catchment area, known as "sink" and then loaded on the truck for the following workmanships. Indeed, having such TIN DEM of the area considered, it is possible to shape the net, so that all the fruits can roll down in the harvest tanks. The problem of obtaining a suitable shape of the net regards the design process of pretensioned structures such as cable nets and membrane structures. Available design methods have in common that no material laws are

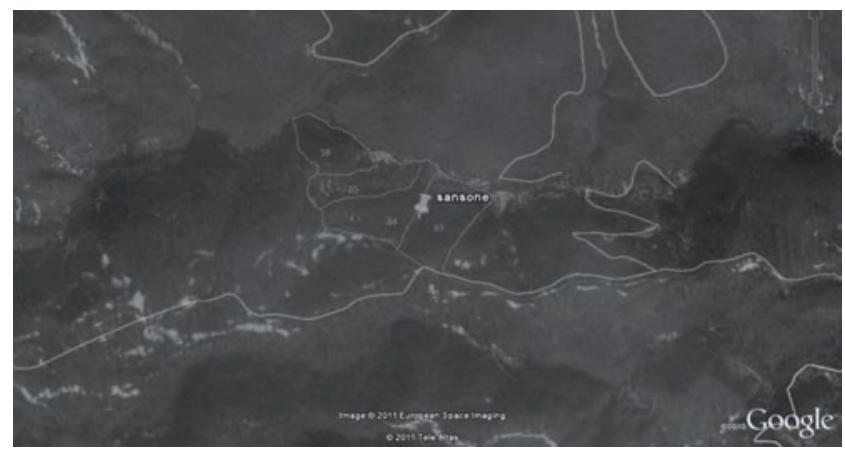

Figure 1. Site map considered.

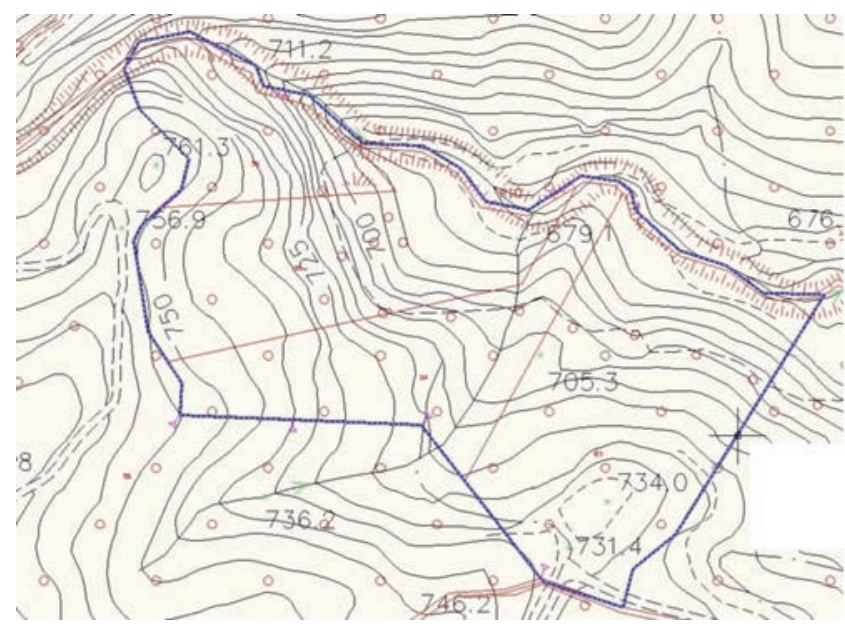

Figure 2. Site map with level quotes. 
necessary to find an equilibrium of the three dimensional shape for given stress distributions, boundary conditions and supports. These shapes of equilibrium should ensure in the built structure an homogeneous distribution of the tension stresses. In reality the material behaviour, process of cutting patterns, manufacturing and pretensioning on site influencing the stress distribution, wrinkles and regions of over stress are obvious, can be seen and measured. (Figure 7)

\section{Nets for chestnuts conveyance and harvest}

Particular types of nets has been considered and precisely: ELAION CANDIA: Strong and heavy net, is defined "anti -thorn" since the textile scheme reduces the possibility of rubbing or hookup, determined by brambles and asperity of the soil. Net with high no-break-up characteristic, weights g. $95 / \mathrm{m}^{2}$, green color. The considered net has the characteristic followings: low weights, resistance to the tear, low wrinkledness to facilitate the slip/rolling of the fruits, not expensive, large versatility of assemblage; possible versatility to use it, in the harvest yards of other fruits in hull (core) in the steep zones.

\section{Tension structures design}

The design process of tension structures such as double curved cable nets or membrane structures such as tents can be divided into form finding, static analysis and cutting pattern. The result of the form finding is a shape of equilibrium for a certain stress distribution and boundary conditions. The shape of equilibrium ensures the geometry of the double curved surface which has only tension and avoids compression in the surface. From this geometry the structural behaviour is exanimated and the cutting pattern is made. An enhanced design concept is based on five design steps defining the shape of equilibrium, generating the cutting pattern, reassembling and pre-tensioning the cutting pattern, the structural analysis of the reassembled structure and the evaluation of the structural behaviour. The material behaviour is considered in the last three steps: flattening the shape of equilibrium, reassembling and load bearing behaviour. The length and the width of the strips has an influence to the shear deformation of the coated fabric. The orthotropic behaviour of coated fabric influences the process of pretension and the stress distribution in the reassembled structure. The numerical process allows after evaluation modifications to reach better results in the reassembled structures considering stress distribution and deformations. (Figure 8). The development of Computer Aided Design marked the start of changes in geometry endorsing new and free forms. This generation of double curved 3dimensional surfaces is restricted by few limitations. Theoretically there are an unlimited number of forms to be numerical generated and represented. However, the manufacture and realization of such double curved surfaces are subject to numerous boundary conditions and restrictions. Using cables and membranes for the load transfer only tension forces can be carried, the cables and membranes can not withstand bending moments and compression forces in a global point of view. The structures have to be pre-tensioned in order to activate the geometric stiffness or to be able carrying compression forces by reducing the pretension. The shape of equilibrium defines a pre-tensioned geometry of a doubled curved surface for a cable net or a membrane structure. The relation between the tension stress, geometry and equilibrium allows three possibilities to introduce the tension into the membranes and influences the shape of equilibrium (Figure 9). Membrane - textile structures can be designed in three general ways.

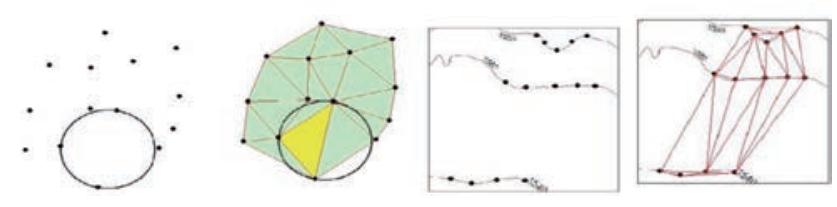

Figure 3. Delaunay triangulation.
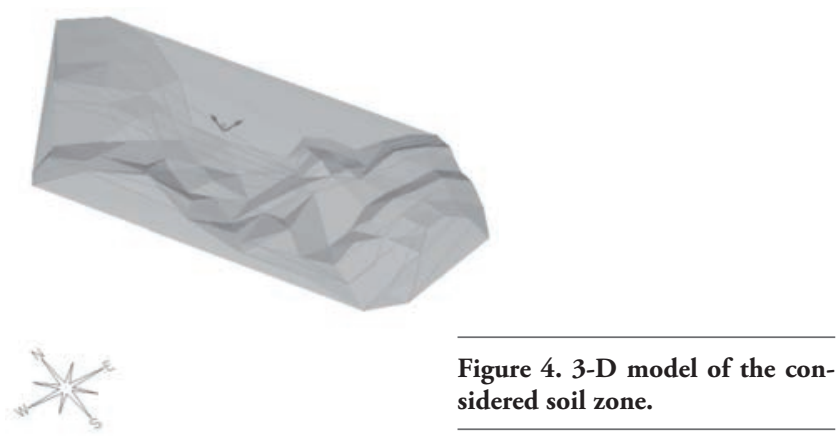

Figure 4. 3-D model of the considered soil zone.

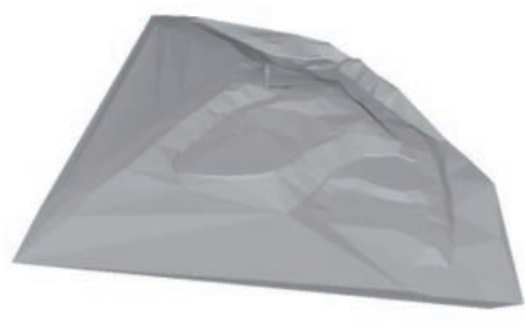

Figure 5. 3-D TIN DEM model of the considered soil zone.

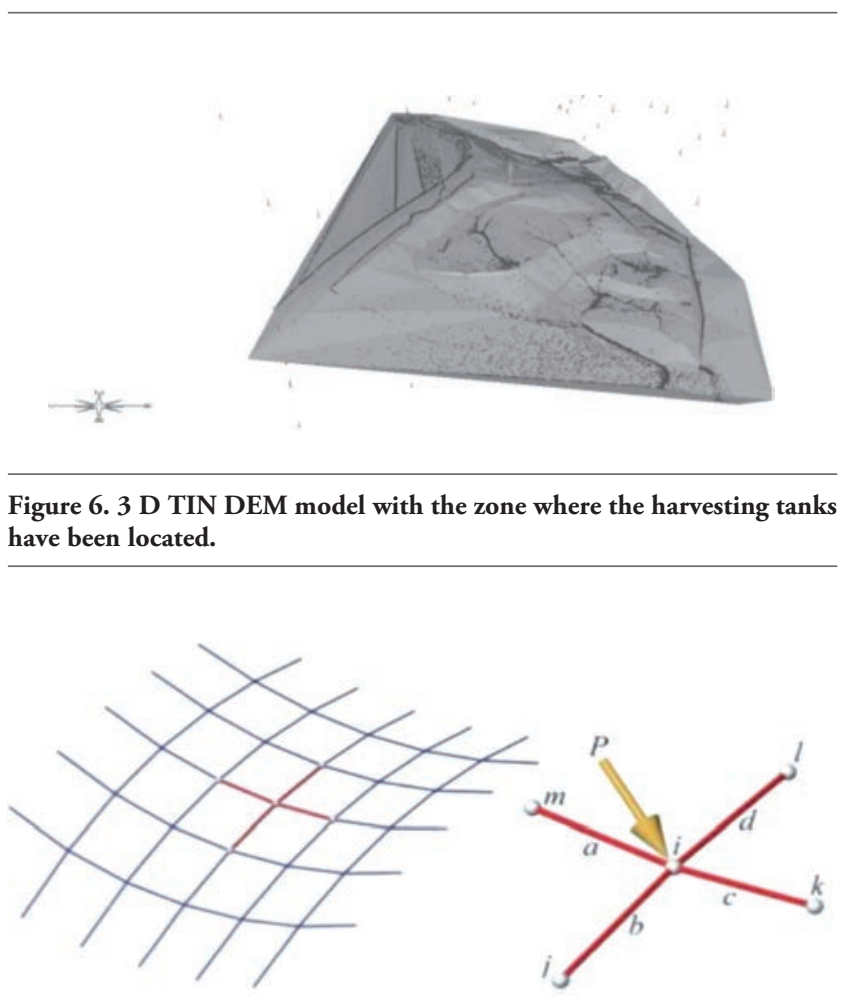

Figure 7. Part of a cable network. 
Non-computational: physical models are used to form-find the prestress surface geometry and create the cutting patterns. Simplified "hand calculations" are used to predict structural response.

Non-specialised software: non-equilibrium computational modelling software, such as 3DS Max, is used to generate the pre-stress surface geometry and cutting pattern generation. Standard finite element (FE) software, such as Ansys 14.5 code, is used to perform non linear structural analysis.

Specialised software: lightweight structure task-specific equilibrium based computational modelling software is used to perform form-finding, load analysis and cutting pattern generation. The non-computational method has the advantages that it is intuitive, the form can be realised, it can be implemented with low initial investment, and modification of conceptual forms is quick and simple. It suffers from its lack of computational non-linear structural analysis, low precision and lack of computational mesh for rendering. Its slowness, particularly with respect to making modifications to the production form and cutting patterns, makes it operationally expensive. Using the non-specialised software method leverages existing $\mathrm{CAD}$ and analysis software skills and provides many sophisticated geometric tools. With few exceptions, the forms generated are, however, not force equilibrant. Consequently they can not necessarily be realised with a tensile surface. Lack of integration between the mesh generation and analysis leads to slow design modification cycles. Conventional FE software is often inappropriate for use with textile models. In particular, convergence problems are usually experienced by standard FE systems when dealing with textile slackening on-off non-linearity. Specialist textile structure software systems quickly provides high confidence, high precision, integrated solutions. Initial investment is higher but when design volume is adequate, per-design costs are low.

\section{Experimental tests}

In the case in study, a farm has been considered constituted by around 10 hectares of chestnut tree. In a meaningful part of the considered area, because of the high slope, the harvest and the workmanships of cleaning pre-harvest, they are effected completely by hand. The tests have been performed in a chestnut tree plant of about 25 years of age, constituted by a steep soil, with different slope values. The nets were located following the optimal shape determined by using machines aiding the operation of net rewind.(Figure 10 and Figure 11). Insofar , experimental tests have been effected both on the materials of the considered nets and on the realized equipments, and models have been used for verifying the obtained results. For the forces' determination, the structural parts have been sensitized, opportunely through movements and strengths transducers connected to a system of data acquisition with frequency of sampling of $1 \mathrm{hz}$. The equipment is composed by tubular structure, transportable by mean the pitchforks of the anterior lifter of the tractor. It is possible to move the tool with a lifter connected to the three back points. The structure contains a galvanized plate tank for the chestnuts and two sidely arms sustaining the net. The tank for the chestnuts has an opening with counter for the transfer of the chestnuts in the large case for the transport. The arms sustaining the net are composed by 2 segments that refold on it.

\section{Data results analysis}

The nets have been located following the determined optimal surface (Figure 12 and Figure 13). In such way all the chestnuts have been

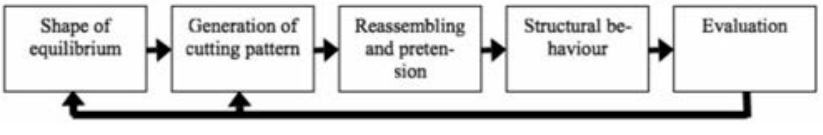

Figure 8. Enhanced design process of membrane curvature.
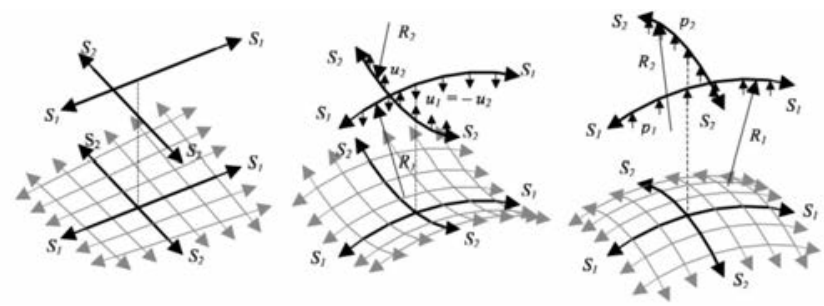

Figure 9. Relation between tension forces and curvature.

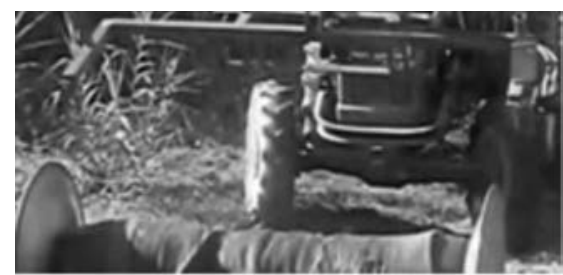

Figure 10. Aiding machine to rewind the nets.

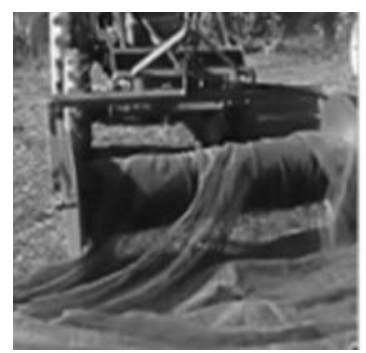

Figure 11. Aiding machine to rewind the nets.

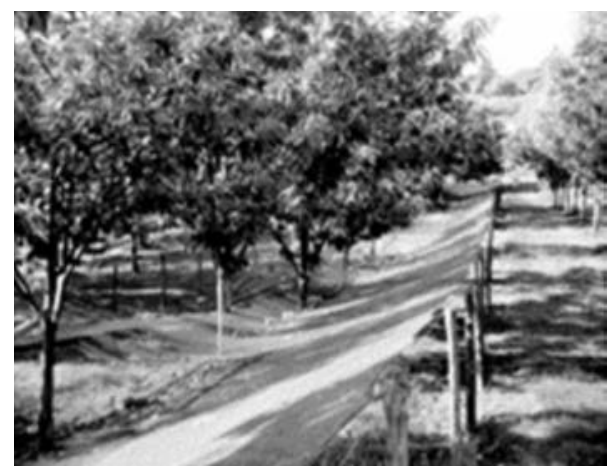

Figure 12. Harvest nets.

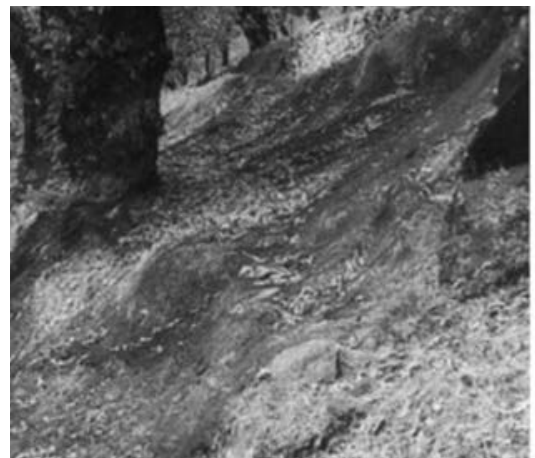

Figure13. Harvest nets. 
picked in an only determined zone, "basin zone", and subsequently they have been loaded on the truck for the following workmanships. The evaluated losses have been of around 6-8 \% due to chestnuts entangle or little branches obstacle. The picked production during the tests has been determined by the presence of a notable quantity of product on the soil $\left(0,264 \mathrm{~kg} / \mathrm{m}^{2}\right)$.The analysis of the picked product has been effected, to the purpose to underline the working quality performed by the harvest system considered. It is been noticed as in the picked product there were impurities equal to $2,2 \%$. Such level of cleaning can also be defined good in consideration of the washing operation in water of the chestnuts that is performed as a rule subsequently in the farm center.

\section{Conclusions}

An application of software for the optimization of the surface shape of nets for chestnut harvesting has been set-up, for steep soil (slope $>25 \%$ ), not being possible some type of mechanization, then nets opportunely designed have been used. Such nets have been installed according to a geometry determined through computational codes, in way that the chestnuts, when they fall, because the geometry of the nets used, they are convoyed in the harvest tank. Besides with such research it has been validated the use of machine to stretch and to rewind the nets. Such machine has resulted, not heavy, manageable and effective.

This research is at the basis of possible further development of the study aimed to reduce the "mountain marginal areas", that is to obtain a productive activity in this type of areas, avoiding the abandonment of them.

\section{References}

Bassi D., Casiraghi M.C., Magnani I., Vercesi A., Delaidelli G. 2001 Effetto dei trattamenti post raccolta e dei metodi di conservazione sulla qualità delle castagne. In: Atti del convegno nazionale sul castagno 2001, Marradi 25- 27 ottobre 2001, 244-249.

Bergantz R. 1987. Experiences with the California chestnut industry. In Proceedings of the Second Pacific Northwest Chestnut Congress, Oregon State University.33-5 l.

Biondi P., Monarca D., Panaro V. 2001. Influenza della raccolta meccanica delle castagne sulla qualità dei frutti raccolti. Convegno Nazionale Castagno 2001.

Formato A., Scaglione G.P, Carillo M., Federico R. 2008. Performance Evaluation of Pneumatic Machines for Hazelnut Harvesting Conv. AgEng2008. Hersonissos. Crete. Greece. 23-25 June 2008.

Formato A., Scaglione G., Pucillo G., Abagnale A., Milano G. 2011. Chestnuts facilitated harvest systems in steep zones XXXIV CIOSTA CIGR V Conference 2011: Efficient and safe production processes in sustainable agriculture and forestry 29 June - 01 July 2011 Vienna, Austria. ISBN:978-3-200-02204-1

Formato A., Guida D., Lenza A., Palcone C., Scaglione S. 2012. A machine prototype for the chestnut mechanical harvest in steep zone. CIGR-AgEng2012 International Conference of Agricultural Engineering. Valencia, Spain - July 8 - 12, 2012.PAPERS B00K. ISBN 10 84-615-9928-4 and ISBN13 978-84-615-9928-8

Formato A., Guida D., Lenza A., Palcone C., Scaglione G. 2012. A machine to improve the safety during the chestnut mechanical harvest in steep zone. International Conference RAGUSA SHWA "Safety Health and Welfare in Agro-food Agricultural and Forest Systems". September 3-5, 2012 Ragusa - Italy. ISBN 978-88905473-4-8

Monarca D., Cecchini M., Massantini R., Antonelli D., Salcini M.C., Mordacchini M.L. 2004. Mechanical harvesting and quality of "marroni" chestnut. Acta Horticolturae.

New E. 1988. The chestnut industry in New Zealand. Proc. 2nd PNW Chestnut Congress. Chestnut Growers Exchange P.0. Box 12632, Portland, OR 97212. OR Dept. Ag. Chestnut blight quarantine 1987. OAR 603-52-075. Oregon Dept. Agric., 635 Capitol Street NE, Salem, OR 97310.

Rutter P. 1987 . Chestnut ecology and the developing orcharding industry. In Proceedings of the Second Pacific Northwest Chestnut Congress, Oregon State University. 